\title{
ACUTE CORD REPERFUSION INJURY AFTER POSTERIOR CERVICAL DECOMPRESSION FOR CHRONIC POSTERIOR LONGITUDINAL LIGAMENT OSSIFICATION STENOSIS
}

(1) Bashar Abuzayed1', (1) Khaled Alawneh², (1) Eyad Kharroub³, (1) Majdi Al-Qawasmeh4, (1) Liqaa Raffee 5

\author{
${ }^{1}$ The Specialty Hospital, Clinic of Neurosurgery, Amman, Jordan \\ 2Jordan University of Science and Technology Faculty of Medicine, Department of Radiology, Irbid, Jordan \\ ${ }^{3}$ The Specialty Hospital, Clinic of Anaesthesiology and Reanimation, Amman, Jordan \\ 4Jordan University of Science and Technology Faculty of Medicine, Department of Neurology, Irbid, Jordan \\ 5Jordan University of Science and Technology Faculty of Medicine, Department of Accident and Emergency, Irbid, Jordan
}

A 63-year-old male patient was referred to our outpatient clinic with complaints of upper and lower limbs weakness, which started progressively 5 years ago. Cervical X-ray and magnetic resonance imaging showed straitening of the cervical column in a fixed flexion position and fusion of the vertebral bodies, with diffuse type posterior longitudinal ligament ossification with secondary canal stenosis. The patient was operated with C2-T2 laminectomy. In the immediate post-operative period, the patient was conscious. However, he was unable to breath by himself with insufficient respiratory tidal volume and worsening of the weakness of the extremities. Emergency cervical computed tomography scan showed proper decompression of the cervical canal, no evidence of haemorrhage, and enlarged oedematous spinal cord. The patient was diagnosed of post-decompression reperfusion injury with secondary diaphragm paralysis. Ventilation and medical treatment were applied to manage the situation and the patient improved in his lower limbs motor power and in the tidal volume. The decision was to transfer the patient to another rehabilitation centre to continue treatment.

Keywords: Blood spine barrier, spinal decompression, posterior longitudinal ligament ossification, white cord syndrome

\section{INTRODUCTION}

Sudden neurological deterioration due to acute spinal cord reperfusion injury following spinal decompression is a rarely reported incident in literature. Post-operative magnetic resonance imaging (MRI) shows that cord ischaemia and oedema are characterised by a hyperintense intrinsic cord signal, which is typically addressed as the "white cord syndrome"(1). Although documented in few cases in literature, this pathology is rarely reported after decompression for posterior longitudinal ligament ossification (PLLO) ${ }^{(2)}$.

\section{CASE REPORT}

A 63-year-old male patient with a medical history of Diabetes Mellitus was referred to our outpatient clinic with complaints of upper and lower limbs weakness, which started progressively 5 years ago. Neurological examination revealed upper limb weakness (3/5) and lower limb weakness (2/5). Hyposthesia was in all extremities with hyper-reflexia in both lower limbs. Examination of the neck revealed fixed flexed position of the head with limited neck movement, especially of the flexion and extension. Cervical X-ray showed straitening of the cervical column with fixed flexion position and fusion of the vertebral bodies. Cervical MRI was done in a specialised imaging centre while the neck was in flexion position. The MRI showed the diffuse type PLLO with secondary canal stenosis (Figure 1). As a differential diagnosis diffuse idiopathic skeletal hypersoteosis was considered and accordingly dorsal and lumbosacral spine X-rays were performed and showed no calcification or ossification of soft tissues (ligaments and enthuses) and no sacroiliac joint fusion. These findings favoured the diagnosis of cervical diffuse PLLO.

A decision to perform only laminectomy from $\mathrm{C} 2$ to $\mathrm{T} 2$ without fixation as the vertebral bodies were already fused was made after discussion on the case. The patient was prepared for

Address for Correspondence: Bashar Abuzayed, The Specialty Hospital, Clinic of Neurosurgery, Amman, Jordan Phone: +962 798392121 E-mail: sylvius@live.com Received: 26.05.2020 Accepted: 28.06.2020

ORCID ID: orcid.org/0000-0002-9298-9914 
surgery and laboratory results showed no abnormalities. The patient was operated in prone position.

Wide laminectomy was performed starting from C2 level to T2 level, and the spinal cord was

decompressed (Figure 2A). The surgery was uneventful and vital signs were stable with no fluctuations or unusual recordings. After decompression, bulging of the spinal dura was noted and with gentle palpation the dura was found unusually tense.

In the immediate post-operative period, the patient gained consciousness. However, he was unable to breath by himself with a respiratory tidal volume of $50 \mathrm{~mL}$. Neurologic examination revealed worsening of the weakness of all extremities (1/5), with profound hyposthesia in all extremities. The patient remained intubated and an emergency cervical computed tomography (CT) scan was performed and it showed proper decompression of the cervical canal, and no evidence of haemorrhage, however, enlarged oedematous spinal cord (Figure 2B and C). The first decision was to perform an MRI, but the MRI machine in the centre was not good enough to insert the patient with fixed flexed neck and the condition of the patient was not good for transfer to another imaging centre. So, the CT scan was performed to exclude surgically treatable possible complications, such as hematoma. The patient was diagnosed with post-decompression reperfusion injury with secondary diaphragm paralysis and was transferred to the intensive care unit. The ventilator setting was synchronized intermittent mandatory ventilation (SIMV) mode and medical treatment started with high doses of dexamethasone, citicoline, Nucleo-CMP, cyano-cobalamine injections, and intravenous vitamin C. In the early post-operative period, the patient showed improvement in lower limbs motor power (3/5) and in the tidal volume $(500 \mathrm{~mL})$. The patient did not show neuropathic

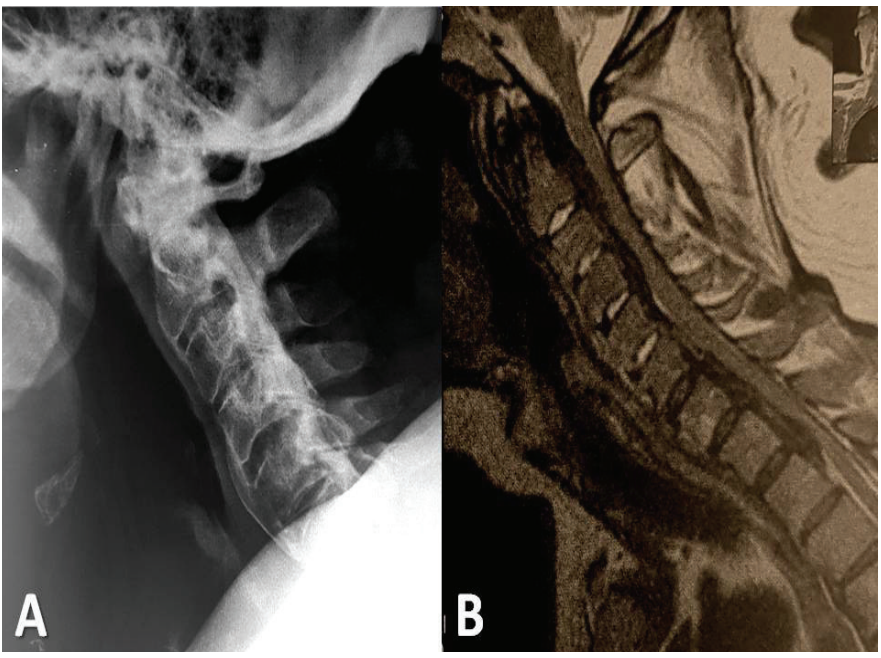

Figure 1. Pre-operative A) lateral cervical X-ray and B) T2-weighted sagittal cervical MRI demonstrating the diffuse type PLLO and secondary canal stenosis, with fusion of vertebral bodies and straitening of the cervical spine with fixed flexion position

PLLO: Posterior longitudinal ligament ossification, MRI: Magnetic resonance imaging pain. Instead, he continued to suffer from hyposthesia in all extremities. It may be was due to the extensive neural injury which might be included the sensory pathways. The patient was fully awake and felt discomfort with the endotracheal tube. For this reason, with the expectation of the long term need for the ventilator, tracheostomy was opened in the post-operative day 7 . In the post-operative day 10 , the tidal volume was around $700 \mathrm{~mL}$ and the respiratory mode was alternating between SIMV and continuous positive airway pressure therapy. The patient was later transferred to another rehabilitation centre.

\section{DISCUSSION}

Posterior cervical decompression is a common surgical technique indicated for pathologies resulting in symptomatic spinal cord and/or root compression. Vascular insult such as ischaemia/reperfusion injury can develop due to rapid cord oedema after acute increased blood perfusion to the affected area ${ }^{(1,2)}$. In the case of our patient, the diffuse type PLLO with secondary chronic canal stenosis produced a large area of cord oedema. The source of the acute cord injury was likely due to the sudden decompression of the spinal cord. This led to disruption in the blood-brain and the blood-spinal cord barriers. The end result was reperfusion injury of the cord ${ }^{(1)}$.

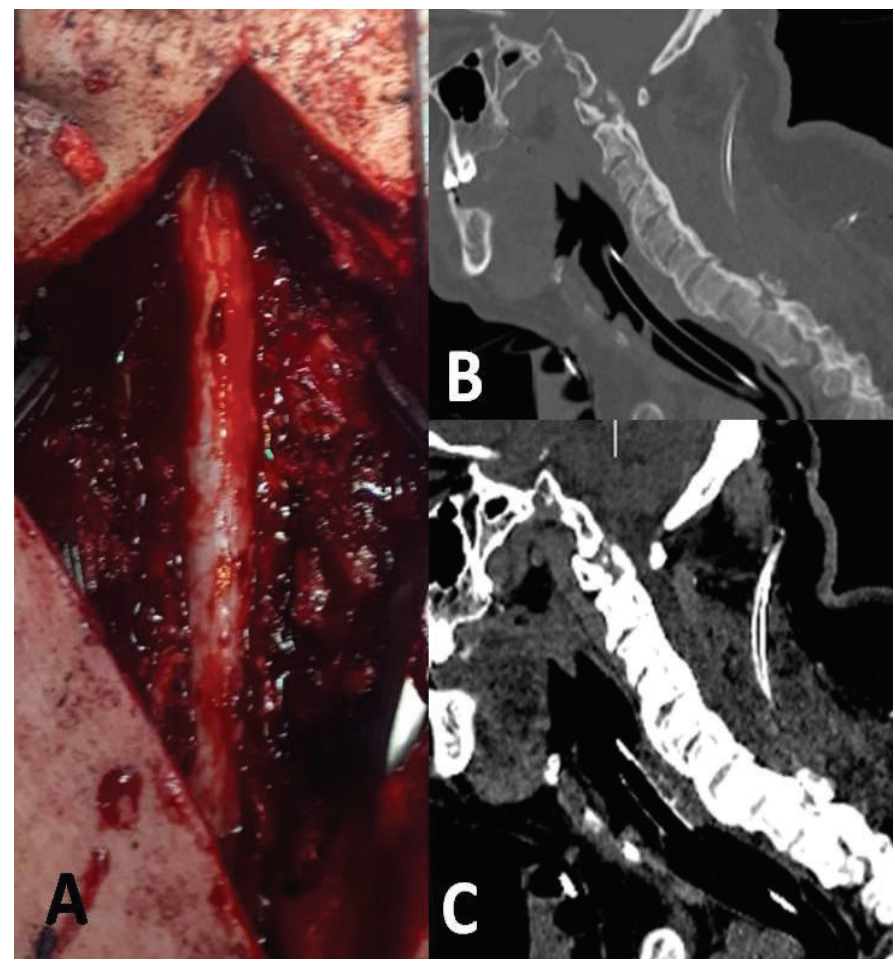

Figure 2. A) Intra-operative view after C2-T2 laminectomy showing the decompression of the spinal cord and bulging of the thecal sac, B) Bone window and C) soft tissue window sagittal cervical $\mathrm{CT}$ scan showing the decompression of the cervical spinal canal. The soft tissue window shows haemorrhage, but signs of cord oedema demonstrated increased volume and hypodensity of the spinal cord

$\mathrm{CT}$ : Computed tomography 
Spinal cord ischaemia/reperfusion injury has also been shown to be related to free radical-related neural injury, mitochondriadependant apoptosis, TNF- $\alpha$ production, and specific phospholipid signalling cascades resulting in neuronal injury in animal models and human studies ${ }^{(2-4)}$. Studies suggested that spinal cord ischaemic injury results in detachment of astrocyte foot processes from endothelial cell surfaces, thus inhibiting tight junction function in the blood-brain barrier $(B B B)^{(3-5)}$, leading to the disruption of transport systems and ionic buffering and enhancing the passage of blood borne or neurotrophic substances (specifically TNF- $\alpha$ ) through the BBB past saturation point ${ }^{(3,4)}$.

Experimental studies showed that post-operative acute increase in the production of cytokines within the spinal cord was independent of the time of surgical intervention ${ }^{(6)}$. Delayed surgical decompression resulted in unresolved cytokine production (up to 5 weeks following decompression), sustained astrogliosis, and systemic increase in the ratio of peripheral inflammatory/patrolling blood monocytes. This showed absence of neurological improvement. Contrarily, early decompression resulted in resolution of inflammation and astrogliosis and was associated with neurological recovery in the upper and lower extremities, and improvement of pain in the upper extremities. Post-operative abnormal expansion of the T2 high signal intensity was documented in $6.1 \%$ of the patients, which is typically labelled as the "white cord syndrome"(7). Of these patients $43 \%$ were asymptomatic ${ }^{(7)}$. In the symptomatic patients, typical clinical finding was diffuse paresis of the upper limbs without deterioration of lower limbs, as seen in our case. However, definite radiologic diagnosis of white cord syndrome in our patient was not available due to the lack of post-operative MRI due to technical issues. Thus, it is considered as a possible diagnosis bases on the clinical picture and course.

The treatment of acute spinal cord reperfusion injury is challenging, and there are no precise guidelines described in literature for the treatment of this specific condition. There is a general direction to treat this pathology as acute spinal cord injury in spite of the aetiology. Treatment with high doses dexamethasone IV $4 \mathrm{mg} \times 4$, citicoline IV $1 \mathrm{gr} \times 2$, NucleoCMP forte tablet (Cytidine $5 \mathrm{mg}$ and Uridine - 5'- trisodium triphosphate $1.33 \mathrm{mg}$ ) $2 \times 2$, cyano-cobalamine $1000 \mathrm{mcg} / \mathrm{mL}$ IM $1 \mathrm{~mL} \times 1$ for 10 days and vitamin C IV $500 \mathrm{mg} \times 1$ for 5 days were reported and clinical studies showed their efficiency in the treatment of spinal cord injury ${ }^{(8-10)}$. These medications were used in our case with observation on the improvement of our patient. Moreover, based on the National Acute Spinal Cord Injury Study II and III trials, methylprednisolone is currently recommended for the management of acute spinal cord injury ${ }^{(11)}$. These trials demonstrated the fast acting and effectiveness of methylprednisone in improving motor scores in acute spinal cord injury patients when compared to placebo $^{(11)}$. However, due the medical condition of our patient with difficult controlled diabetes and metabolic disturbances, the medical and intensive care unit team preferred to avoid methylprednisolone treatment in our patient and replaced it with dexamethasone instead.

\section{Ethics}

Informed Consent: The patient signed an informed consent form.

Peer-review: Externally peer-reviewed.

\section{Authorship Contributions:}

Surgical and Medical Practices: B.A., E.K., Concept: B.A., E.K., L.R., Design: M.AQ., Data Collection or Processing: K.A., Analysis or Interpretation: M.AQ., Literature Search: K.A., L.R., Writing: B.A.

Conflict of Interest: No conflict of interest was declared by the authors.

Financial Disclosure: The authors declared that this study received no financial support.

\section{REFERENCES}

1. Vinodh VP, Rajapathy SK, Sellamuthu P, Kandasamy R. White cord syndrome: A devastating complication of spinal decompression surgery. Surg Neurol Int. 2018,13;9:136.

2. Chin KR, Seale J, Cumming V. "White Cord Syndrome" of Acute Tetraplegia after Anterior Cervical Decompression and Fusion for Chronic Spinal Cord Compression: A Case Report. Case Rep Orthop. 2013;2013:697918. doi: 10.1155/2013/697918

3. Pan W, Banks WA, Kastin AJ. Blood-Brain Barrier Permeability to Ebiratide and TNF in Acute Spinal Cord Injury. Exp Neurol. 1997;146:367-73.

4. Yu F, Kamada H, Niizuma K, Endo H, Chan PH. Induction of MMP9 Expression and Endothelial Injury by Oxidative Stress after Spinal Cord Injury. J Neurotrauma. 2008;25:184-95.

5. Anik I, Kokturk S, Genc H, Cabuk B, Koc K, Yavuz S, et al Immunohistochemical analysis of TIMP-2 and collagen types I and IV in experimental spinal cord ischemia-reperfusion injury in rats. J Spinal Cord Med. 2011;34:257-64.

6. Vidal PM, Karadimas SK, Ulndreaj A, Laliberte AM, Tetreault L, Forner $S$, et al. Delayed decompression exacerbates ischemia-reperfusion injury in cervical compressive myelopathy. JCI Insight. 2017, 2;2(11). 10.1172/jci.insight. 92512

7. Seichi A, Takeshita K, Kawaguchi H, Nakajima S, Akune T, Nakamura K. Postoperative expansion of intramedullary high-intensity areas on T2-weighted magnetic resonance imaging after cervical laminoplasty. Spine (Phila Pa 1976). 2004;29:1478-82.

8. Kaplan T, Kafa IM, Cansev M, Bekar A, Karli N, Taskapilioglu MO, et al. Investigation of the dose-dependency of citicoline effects on nerve regeneration and functional recovery in a rat model of sciatic nerve injury. Turk Neurosurg. 2014;24:54-62.

9. Gella A, Martiañez T, Lamarca A, Gutierrez C, Durany N, Casals N. A nucleotide-based Drug Protects Against Glutamate- and MPP+Induced Neurotoxicity. Neuroscience \& Medicine 2011;2:154-60.

10. Lee JY, Choi HY, Yune TY. Fluoxetine and vitamin C synergistically inhibits blood-spinal cord barrier disruption and improves functional recovery after spinal cord injury. Neuropharmacology. 2016;109:78-87.

11. Bracken MB, Shepard MI, Holford TR, Leo-Summers L, Aldrich EF, Fazl $M$, et al. Administration of Methylprednisolone for 24 or 48 Hours or Tirilazad mesylate for 48 Hours in the Treatment of Acute Spinal Cord Injury. Results of the Third National Acute Spinal Cord Injury Randomized Controlled Trial. National acute spinal cord injury study. JAMA 1997;277:1597-604. 